\title{
Developing a quality management tool for preparing Good Distribution Practice audit of pharmaceutical contract vaccine distributor
}

\author{
Stana Bekčića ${ }^{\star a}$, Nenad Kelečevića, Valentina Marinkovićb, Ljiljana Tasićb and Dušank ${ }^{a}$ Krajnovićb $^{b}$ \\ aQuality Assurance Department Institute of Virology, Vaccines and Sera, “Torlak”, Belgrade, Republic of Serbia \\ ${ }^{b}$ Department of Social Pharmacy and Pharmaceutical Legislative University of Belgrade, Faculty of Pharmacy, Republic of Serbia
}

\begin{abstract}
Outsourcing is increasingly used by the vaccine manufacturers. When the manufacturing activities are outsourced, the contract manufacturer's Good Manufacturing Practice compliance needs to be confirmed through auditing. In the same way, when distribution is outsourced, the contract distributor's Good Distribution Practice compliance needs to be confirmed through auditing. The objective of this study was to develop an audit preparation tool for the pharmaceutical contract vaccine distributor and to validate its contents by using the Delphi method. Based on this, a tool was developed for the contract vaccine distributors. The Delphi method was used with a group of 14 experts from the pharmaceutical industry, authorities and university. The response rate in the Delphi questionnaire round was $100 \%$. The tool consisted of 33 quality items, out of which 29 (88\%) achieved the pre-defined agreement rate level $(>75 \%)$. The four quality items which did not achieve the pre-defined agreement rate were excluded from the tool. The expert group suggested only minor changes to the tool. The results show that the content validity of the developed audit preparation tool was good. The resultant questionnaire is ready to use. Developed the ready-to-use questionnaire based on critical factors evaluation, gives an objective picture of the possibilities of the potential partner and help organisations make quality decision on the selection of contract vaccine distributors. The contract vaccine distributor must be permanently controlled and analysed, so as to maintain the required quality and to keep low level of costs.
\end{abstract}

Key words: Audits, Delphi method, GDP, Pharmaceutical industry, Quality management.

\section{INTRODUCTION}

Reliance on vaccine safety is of critical importance for the national immunisation strategies and for the global public health. ${ }^{4}$ In order for a safe and secure medicinal product to reach the end-user, distribution process plays an important role in the quality maintenance chain, complying with the Good Distribution Practice (GDP) guidelines ${ }^{5}$. Taking over the responsibilities for maintaining top quality of a medicine/ product starting from production, through distribution, storage, dispensing or sales, to the end-user, is a professional obligation and ethical responsibility of all healthcare professionals in the medicinal products supply chain. ${ }^{5}$ The quality of medicinal product should remain identical until the end-user in accordance with the relevant marketing authorisation (MA). The concept of quality management and QMS requirements in a distribution chain should be in accordance with the GMP guidelines. ${ }^{5}$ Socially accountable companies in the pharmaceutical supply chain are faced with the fact of having to establish a growing number of standards which are a necessary condition for doing business and market survival. ${ }^{6}$ The quality system (QS) of pharmaceutical wholesalers should ensure that only medicinal products with the MA are distributed, that medicinal products storage conditions are under constant supervision, that the possibility of medicinal products contamination or cross contamination is minimized during trans-
Submission Date : 17-09-2014 Revision Date : :08-01-2015 Accepted Date : :05-02-2015

DOI: 10.5530/ijper.49.3.2 Correspondence Address Prof. Stana Bekčić Institute of Virology, Vaccines and Sera,

"Torlak", Belgrade, Republic of SerbiaSerbia, 11000 Belgrade, Borivoja Stevanovića $12^{\circ}$

Email:sbekcic@gmail.com

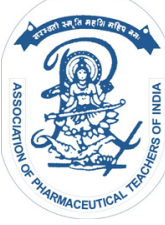

www.ijper.org 
port, that the medicinal products are adequately handled in the store, and that all medicinal products are kept in a proper, safe place. The quality system, among other things, should also meet the requirement that the right product is delivered to the right address within a satisfactory period of time. Monitoring medicines through distribution channels should ensure easy detection of defective products, and recall procedure should be efficient and quick. ${ }^{7}$ In comparison with the vaccine production costs, the distribution chain investments are marginal, but absolutely critical if we want to see the benefit from vaccines. ${ }^{8}$ Researchers showed that very few people have a bird's eye view of various health systems components and interactions between programmes and can comment competently on issues, such as distortion of priorities and opportunity costs. ${ }^{9}$ This fact emphasize the need of standardize comprehensive procedures.

The pharmaceutical industry is confronted with constant challenges. On one side there is legislation requiring the production of quality, efficient and safe medicinal products, and on the other, great pressure to reduce the price of medicinal products, thus imposing the demand for costs reduction on pharmaceutical companies. ${ }^{10}$

Taking these facts into account, the companies focus on the development of their core activities, while the non-core activities are outsourced to contractors. ${ }^{11}$ Outsourcing activities also carries a greater risk with regard to quality maintenance and regulatory compliance, (e.g.) the outsourced contractor must observe company values and have strong and short lines of communication with the company. Since these requirements imply a high level of association between the partners, the company should have a rationally small number of outsourced contractors with whom strategic partnership has been established.

The specificities of business operations in the pharmaceutical field require a multidisciplinary and careful approach on one side, and quick and comprehensive solutions on the other. Therefore, the process of choosing an external contractor is based on empirical and, as far as possible, adequate criteria for business partner selection. Bearing in mind the previously stated pre-conditions, as well as the responsibility towards patients 'health which rests with the Marketing Authorisation holder, the pharmaceutical company must establish a quality system for selecting and monitoring external contractors.

The first step is choosing a method to perform qualification of the potential external contractor. ${ }^{7}$ The method must be simple and reliable. Simplicity will be achieved by selecting the appropriate form, while reliability will be reached if tests are included referring to the critical points obtained from the risk analysis of the process for which the partner is outsourced. Based on the research results, data will be obtained on the weak points of the potential external contractor. Acceptance criteria can be based on the number of weak points found or on the specific weaknesses. If it is determined that the potential partner meets the pre-defined key aspects, i.e. their number, the selection process can continue.

Vaccines are a heterogeneous class of medicinal products requiring handling in cold chain regime. Therefore, WHO issued a series of guide books aimed at providing all participants in vaccines storage and distribution with clear guidelines and answers, thus reducing the risk of cold chain disruption? Cold chain maintenance in all stages of vaccines handling ensures preserving their stability during the stipulated shelf-life. As a part of a wider picture, this issue is included in the six Building blocks that are considered as a set of inputs that contribute to the desired outcomes of a health system, improved health and health equity, responsiveness, social and financial risk protection and improved efficiency, through improving access, coverage, quality and safety. ${ }^{12}$

The aim of this study was to develop a tool for the preparation of pharmaceutical contract vaccine manufacturer audit. The tool was a questionnaire, with mainly GDPrelated questions, developed based on the questionnaire used by WHO for the certification of companies as the National Vaccine Store. ${ }^{13}$ Unlike the integral WHO questionnaire, which is lengthy in line with its goal, the questionnaire resulting from this work is a practical tool for the public and private sector organizations without any ambitions with regard to WHO certifications. The guiding idea was to make a questionnaire that is easily applicable and reliable. Audit is carried out as a part of the contract distributor selection process,${ }^{14}$ so the purpose of the questionnaire was to obtain preliminary information about the contract vaccine distributor and help prepare for the audit. Since papers on this topic are very few, there is a free room for research in this field which puts this work in the rank of few research papers dealing with this important link in the cold chain. The content validity of the preparation tool was assured by the Delphi method. Guiding idea for the initial selection of questions was choosing the questions regarding critical confidence limits of the distributor's system performance. The selection of the first round questions covers critical points of the process, thus collecting information on the pharmaceutical distributor's capabilities.

\section{MATERIAL AND METHODS}

\section{Design}

Since usage of the chosen solution provides information on weaknesses in the solution, and since the level of experience i.e. the quality of the solution rises with 


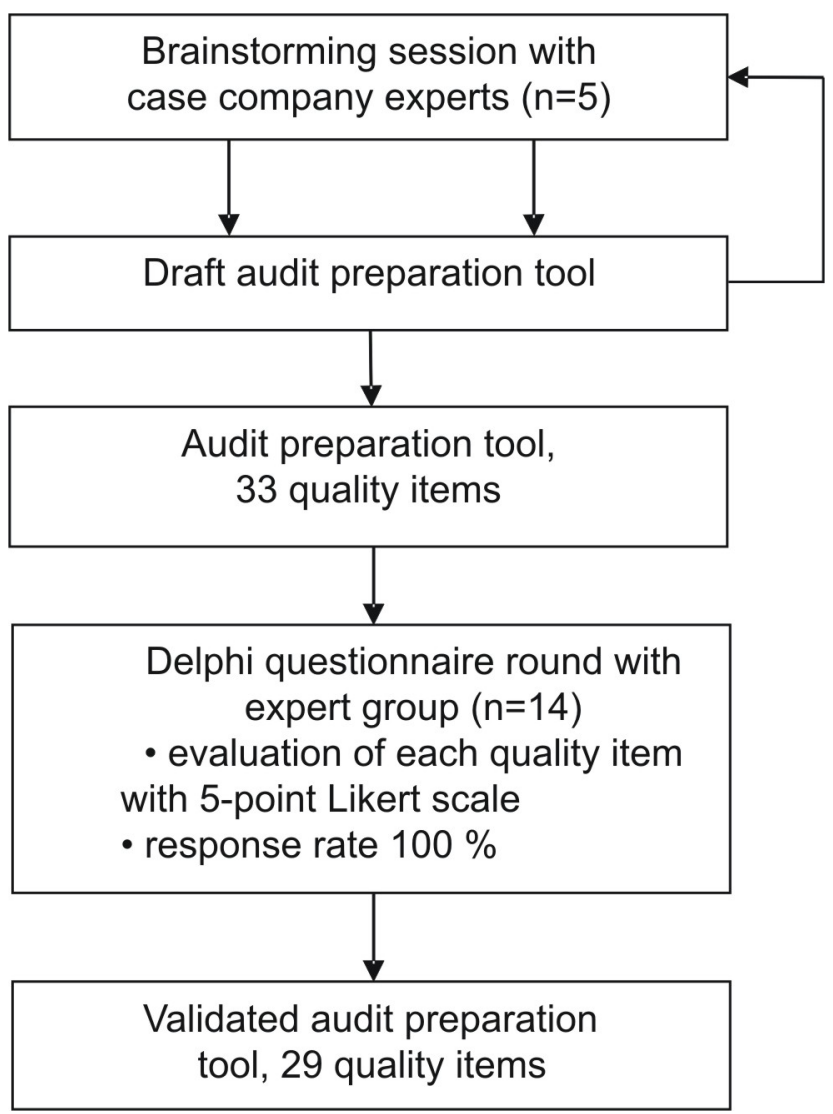

Figure 1: Development of the audit preparation tool ${ }^{7}$

the passage of time, ${ }^{15}$ time for reaching a quality solution was imposed as the key factor in this research.

As a result, a method was chosen which in a short period of time implements the accumulated experience by including experts for the specific field of research. The Delphi method was used in this study. The Delphi method is used for making a group judgement on a topic for which no or unconvincing research-based information exists. In the conventional Delphi method, a small expert group develops a questionnaire, which is then sent to a larger expert group. The questionnaire is modified based on the first results and then re-sent together with the results from the previous round. The research is continued until the consensus has been achieved. ${ }^{16}$

\section{Step 1: Development of the audit preparation tool}

The audit preparation tool was developed together with experts $(\mathrm{n}=4+$ researcher) of the company holding the National Vaccine Store certificate issued by WHO and UNICEF for storage and distribution of the case company's vaccines (Figure 1). The case company is a medium-sized biotechnological company engaged in the production, storage and distribution of vaccines, which has contract with other vaccine manufacturers for storage and distribution of vaccines. The tool was developed for the contract storage and distribution of vaccines. The experts were trained in the course of the certification preparations, followed by the continuing post-certification training. The experts have an extensive experience in auditing vaccines storage and distribution conditions. This experience was used for choosing the questions that could have a key role in drafting the potential partner's capabilities.

\section{Step 2: Delphi questionnaire round}

The content validity of the audit preparation tool was assessed using the Delphi method. An expert group ${ }^{10}$ was recruited to evaluate the tool contents. The expert group consisted of 14 people with extensive experience of pharmaceutical industry and GDP issues. The group had members from the case company, other pharmaceutical companies, from authorities and from the university. The original expert group $(n=5)$ was included in this Delphi questionnaire round.

Each respondent was personally contacted before sending the questionnaire, and the purpose of the Delphi questionnaire was explained to them. The questionnaire had clear instructions how the respondents should fill it in. Anonymity of the participants was ensured, the questionnaires were submitted to each respondent individually, and the responses were processed anonymously ${ }^{17}$.

The developed audit preparation tool was sent to the respondents in July 2013. The expert group was 
requested to evaluate the importance of each quality item in the tool on a 5-point Likert scale ranging from 1 (strongly disagree) to 5 (totally agree). The expert group was also suggested to add questions to the questionnaire and record other comments or ideas relating to the content of the tool. The consensus criterion is the number of responses for one option $>75 \%$ out of the total number of responses for that option. Such quality item was interpreted as essential and was kept in the tool. Otherwise, the quality item could be interpreted as not essential and was excluded from the tool. Similar definitions of consensus have been provided in the literature. ${ }^{18}$

\section{RESULTS}

\section{Step 1}

The original questionnaire consisted of 33 quality items in total from 8 different topics: Receipt, Storage, Cold room capacity, Buildings, Equipment and vehicles, Maintenance of buildings, Equipment and vehicles, Vaccine stock records, Efficacy of vaccine deliveries to the next levels in the distribution system, Written procedures (Appendix 1). The first part of the tool contained general information, such as information on the manufacturing site and contact person. The 7 remaining topics with their contents are presented in Appendix 1 .${ }^{15-23}$ All questions in the tool were close-ended requiring from the respondent to circle one out of five given answers. The consensus on 8 questions was reached in the first round.

\section{Step 2}

The final version of the audit preparation tool was produced in December 2013 from two Delphi rounds. The Delphi questionnaire was sent to 14 experts, all of whom returned the completed questionnaire (response rate 100\%). In the second round, the results from the first round were revealed for the questions that did not reach consensus. The questions that reached consensus in the first round were excluded from the questionnaire in the second round. Based on such obtained information, the expert group gave answers to the questions from the questionnaire for the second round. The level of agreement of the quality items varied from $57 \%$ to $87 \%$ (Appendix 2). After the second round, 4 out of 33 quality items $(12 \%)$ did not meet the pre-defined criteria for agreement rate $(>75 \%)$.

\section{DISCUSSION}

The first audit phase of pharmaceutical distributor's external contractor ${ }^{24,25}$ is based on the principle of creating a preliminary credentials file of the potential con- tractor. It includes points relevant in the experts opinion for the initial evaluation of the organization's capability to respond to the imposed requirements in view of distribution and storage in the pharmaceutical industry. The expert group very quickly reached consensus on the questions to be used. Namely, the requested agreement $>75 \%$ was achieved already in the second round for 29 out of 33 questions.

The expert group reached agreement on all questions in the field: receipt, stock records, further deliveries and written procedures. However, in the fields of vaccines storage, cold room capacity, infrastructure and maintenance, there were questions for which consensus was not reached. These questions were excluded from the final tool, and the experts did not manage to agree on the answers due to different opinions on relevance and purpose of the questions. For example, opinions differed as to whether it is required to calculate the cold room capacity and whether cold room performance test is required to be performed twice a year. In view of these dilemmas, it is good to exclude such questions in this phase so as to reduce the possibility of confusion. In the second phase i.e. on-site audit, however, answers to questions for which consensus was not reached would be sought so as to better estimate the level of business efficiency and degree of agreement with the principles of prevention and reliability.

Since it is necessary to control the key elements as extensively as possible on one side, and on the other side resources such as time and money are limited, the expert group followed these guidelines in their work.

The fields from which the questions were chosen are the key aspects with high values of estimated risk to the process in case of their non-fulfilment. By pinpointing these questions, the risk of unwanted situations, which could potentially occur, is cumulatively reduced. Regardless of the quality of evaluation methods, a continuous and good partner communication could even be a more important factor for achieving the set goals. ${ }^{18}$

\section{CONCLUSION}

It is to be expected that a questionnaire conceived in such a manner, based on critical factors evaluation, gives an objective picture of the possibilities of the potential partner in the fields which are very important for an effective and efficient system functioning but which require longer preparatory operations and greater engagement of the related resources. If the pharmaceutical distributor is able to meet the critical minimum in the tested domain, it can be claimed with certainty that it will also meet other required domains. The contract distributor must be permanently controlled and analysed, ${ }^{26}$ so as to maintain the required quality and to keep low 
level of costs. The organizations that have outsourced distribution activities are satisfied with the resulting effects. ${ }^{27}$ Authors will continue with activities related to contract vaccine distributor's assessments by conducting survey based on validated questionnaire. Further manuscripts are to be expected.

\section{REFERENCES}

1. Good manufacturing practice. Available from: http://ec.europa.eu/health/ documents/eudralex/vol-4/index_en.htm [accessed 09.01.2014].

2. Guidelines on Good Distribution Practice of Medicinal Products for Human Use. Available from: http://ec.europa.eu/health/files/eudralex/vol-4/ gdpguidelines1.pdf, [accessed 09.01.2014].

3. S.M. Campbell, J.A. Cantrill, D. Roberts. Prescribing indicators for UK general practice: Delphi consultation study. BMJ; 321 (2000): 425-28.

4. Janice E. Graham, Alexander Borda-Rodriguez, Farah Huzair, Emily Zinck. Capacity for a global vaccine safety system: The perspective of national regulatory agency. Vaccine; 30 (2012): 4953-4959.

5. Ljiljana Tasić, Valentina Marinković et add. Quality in Pharmacy from Theory to Practice. University of Belgrade, Faculty of Pharmacy; Belgrade 2012: 25, 99.

6. Stana Bekčić, Nenad Kelečević, Valentina Marinković, Ljiljana Tasić and Dušanka Krajnović. Approach to the Integration of Management Systems in a Pharmaceutical Organization. Indian Journal of Pharmaceutical Education and Research 2013; 47(3): 19-25.

7. Annu Linna, Mirka Korhonen, Jukka-Pekka Mannermaa, Marja Airaksinen, Anne Maria Juppo. Developing a tool for the preparation of GMP audit of pharmaceutical contract manufacturer. European Journal of Pharmaceutics and Biopharmaceutics; 69 (2008): 786-92.

8. Michael Zaffran, Jos Vandelaer, Debra Kristensen, Bjørn Melgaard, Pershant Yadav, K.O. Antwi-Agyei, Heidi Lasher. The imperative for stronger vaccine supply and logystic systems. Vaccine 2013; 31S: B73-B80.

9. Mounier-Jack Sandra, Griffiths Ulla K, Closser Svea, Burchett Helen and Marchal Bruno. Measuring the health systems impact of disease control programmes: a critical reflection on the WHO building blocks framework. BMC Public health 2014, 14: 278.

10. K. Clinkscales, H. Geimer. Must for managing contract manufacturers. Pharm. Technol. Eur. 2001; 13: 24-28.

11. J. Bath. Optimising the value of outsource partners. Contract services Europe 2003: 12-16

12. World health organization. Everybody's business: strengthening health systems to improve health outcomes. WHO's Framework for Action. Geneva. World Health Organization 2007.

\section{ACKNOWLEDGEMENTS}

This work is supported by Ministry of Science and education of Republic of Serbia, under the project TR-34007.

13. WHO-UNICEF. Effective Vaccines Store Management Initiatives: Modules 1-4. WHO/IVB/04.16-20, UNICEF/Immunization.03 and 04.01-04

14. Jane Probitts. Auditing in the manufacturing environment. The Quality Assurance Journal, 2000; 4: 193-96.

15. Pedro J. Gris Seoane. Use and limitation of checklists. Other strategies for audits and inspections. The Quality Assurance Journal 2001; 5: 133-36.

16. H. Linstone, M. Turoff. The Delphi method - Techniques and Applications. Addison-Wesley, Reading, MA, 1975.

17. J.A. Cantrill, B. Sibbald, S. Buetow. The Delphi and nominal group techniques in health services research. Int. J. Pharm. Pract. 1996; 4: 67-74.

18. M. Valazza, G. Wada. Creating a successful partnership with a contract manufacturer. Pharm. Technol. Eur 2001; 13: 26-34.

19. WHO. Vaccine stock management, Gudelines for Immunization programme and vaccines store managers. WHO/IVB/06.12.

20. WHO. Gudelines on the international packaging and shipping of vaccines. WHO/IVB/06.23.

21. WHO. Gudelines on the establising or improving primary and intermediate vaccines store. WHO/V\&B/02.34.

22. WHO. User's handbook for vaccine cold rooms and freezers rooms. WHO/ $\mathrm{V} \& \mathrm{~B} / 02.31$.

23. WHO-UNICEF. Joint Statement on Effective Vaccine Store Management. World Health Organization, UNICEF, Effective Vaccine Store Management Initiative. WHO/IVB/04.16, UNICEF/Immunization/04.01.

24. A. Billet. Supplier audits: objectives and limits. STP Pharma Pratiques 2006; 16: 337-43.

25. H. Hayes. Auditing your contractor - the human equation. Pharm. Technol. 2002; 26: 106-12.

26. L. Michalski. Audits aren't enough to ensure quality. Pharm. Technol. 2001; 25: 74-76.

27. Valentina Marinković, Elizabeta Kostić, Ljiljana Tasić, Vidosav Majstorović. Conceptual Model for Outsourcing Process in Pharmaceutical Supply Chain. Indian Journal of Pharmaceutical Education and Research 2013; Vol. 47: $55-61$. 


\section{APPENDIX 1 \\ PHARMACEUTICAL QUALITY SYSTEM COMPLIANCE ASSESMENT QUESTIONNAIRE OF THE VACCINE CONTRACT DISTRIBUTOR}

Note: Please review the Questionnaire carefully prior to filling it out!

\section{Background}

Company name:

Address:

Tel: Web mail:

Main activity

Person who completed the Questionnaire (name, surname, signature, function):

Qualifications of the responsible person for distribution

Total number of employees:

GDP implementation date: No. (please submit a copy)

Other certificates: ISO 9001, ISO 14 001, ISO 27 000, OHSAS 18 000, (please submit a copy)

Note:

Responses were graded according to the Likert scale (1-5), having also weighting factors (0-19\%, etc.) / the same as RADAR methodology. The response is an objective grade given to the question asked, by circling one of the five points.

Response grading:

1 - not true at all / 2 - partly true / 3 - true / 4 - more than true / 5 - absolutely true

\begin{tabular}{|c|c|c|c|c|c|}
\hline Question & \multicolumn{5}{|c|}{ Answer (circle) } \\
\hline \multicolumn{6}{|l|}{ I Vaccine arrival } \\
\hline Are there pre-shipment and arrival procedures in place? & 1 & 2 & 3 & 4 & \\
\hline $\begin{array}{l}\text { Is a satisfactory contingency plan in place in case: } 1 \text { ) flights are } \\
\text { delayed; 2) the airport cold room has failed or 3) transport to the } \\
\text { store is delayed? }\end{array}$ & 1 & 2 & 3 & 4 & 5 \\
\hline $\begin{array}{l}\text { Are cold rooms adjusted for vaccine storage (large enough to } \\
\text { accommodate the largest anticipated vaccine shipment, have a } \\
\text { secure lock, have a continuous temperature recording device)? }\end{array}$ & 1 & 2 & 3 & 4 & 5 \\
\hline $\begin{array}{l}\text { Have staff received training in vaccine storage and } \\
\text { transport? }\end{array}$ & 1 & 2 & 3 & 4 & 5 \\
\hline \multicolumn{6}{|l|}{ Is every vaccine arrival recorded? } \\
\hline \multicolumn{6}{|l|}{ II Vaccine storage } \\
\hline $\begin{array}{c}\text { Do the employees that handle the vaccines know the correct storage } \\
\text { temperature range for each of the vaccines? }\end{array}$ & 1 & 2 & 3 & 4 & \\
\hline $\begin{array}{l}\text { Do the employees that handle the vaccines know which vaccines } \\
\text { will freeze at temperatures below } 0^{\circ} \mathrm{C} \text { ? }\end{array}$ & 1 & 2 & 3 & 4 & 5 \\
\hline $\begin{array}{l}\text { Is there a complete set of manual temperature records for each and } \\
\text { every cold room? }\end{array}$ & 1 & 2 & 3 & 4 & 5 \\
\hline
\end{tabular}




\begin{tabular}{|c|c|c|c|c|}
\hline Is there a tested contingency plan in the event of equipment failure? & 1 & 2 & 34 & 5 \\
\hline Is the plan rehearsed at least once a year? & 1 & 2 & 34 & 5 \\
\hline \multicolumn{5}{|l|}{ III Cold storage capacity } \\
\hline Has the volume calculation been carried out for all vaccines stored? & 1 & 2 & 34 & 5 \\
\hline Have capacities of all cold rooms been calculated? & 1 & 2 & 34 & 5 \\
\hline \multicolumn{5}{|l|}{ IV Buildings, equipment and vehicles } \\
\hline $\begin{array}{l}\text { Is there a separate packing area close to the cold rooms and the } \\
\text { needed packing material? }\end{array}$ & 1 & 2 & 34 & 5 \\
\hline $\begin{array}{l}\text { Is there sufficient space to store packed cold boxes in, or close to } \\
\text { the packing area and can the temperature of the packing area be } \\
\text { maintained between } 15^{\circ} \mathrm{C} \text { and } 25^{\circ} \mathrm{C} \text { throughout the year? }\end{array}$ & 1 & 2 & 34 & 5 \\
\hline $\begin{array}{l}\text { Do the refrigerated vehicles have an up-to-date service record and } \\
\text { are the vehicles fitted with continuous temperature recorders? }\end{array}$ & 1 & 2 & 34 & 5 \\
\hline Are all cold rooms fitted with adequate shelving and alarm systems? & 1 & 2 & 34 & 5 \\
\hline Have workers received training in safe working in cold rooms & 1 & 2 & 34 & 5 \\
\hline $\begin{array}{l}\text { Is there an adopted refrigeration equipment replacement plan in } \\
\text { place? }\end{array}$ & 1 & 2 & 34 & 5 \\
\hline \multicolumn{5}{|l|}{ V Building, equipment and vehicle maintenance } \\
\hline Are there building, equipment and vehicle maintenance plans? & 1 & 2 & $\begin{array}{ll}34 \\
\end{array}$ & 5 \\
\hline Are there records of building, equipment and vehicle maintenance? & 1 & 2 & 34 & 5 \\
\hline Is there an adopted preventive maintenance plan in place? & 1 & 2 & 34 & 5 \\
\hline Are there records of preventive maintenance plan realization? & 1 & 2 & 34 & 5 \\
\hline Are there any procedures for handling in case of equipment failure? & 1 & 2 & 34 & 5 \\
\hline $\begin{array}{l}\text { Are in-house cold room performance checks carried out twice a year } \\
\text { in extreme temperature conditions? }\end{array}$ & 1 & 2 & 34 & 5 \\
\hline \multicolumn{5}{|l|}{ VI Stock records } \\
\hline $\begin{array}{l}\text { Are records about the type, number (in doses), manufacturer, batch/ } \\
\text { lot number, expiry date of the freeze-dried vaccine and diluent } \\
\text { individually maintained? }\end{array}$ & 1 & 2 & 34 & 5 \\
\hline $\begin{array}{l}\text { Do stock records indicate adherence to EEFO principles (earliest } \\
\text { expiry, first out)? }\end{array}$ & 1 & 2 & 34 & 5 \\
\hline $\begin{array}{l}\text { Are damaged/expired vaccines clearly identified in the stock } \\
\text { recording system? }\end{array}$ & 1 & 2 & 34 & 5 \\
\hline Are stock records data backed up as per the determined dynamics? & 1 & 2 & 34 & 5 \\
\hline \multicolumn{5}{|c|}{ VII Effectiveness of vaccine deliveries to the next level of distribution } \\
\hline $\begin{array}{l}\text { Did the primary store send a programme (announce delivery) to the } \\
\text { intermediate store setting out dates for the delivery and/or collection } \\
\text { of vaccines? }\end{array}$ & 1 & 2 & 34 & 5 \\
\hline $\begin{array}{l}\text { Is the reliability of actual delivery/collection dates against the } \\
\text { programme between } 90 \% \text { and } 100 \% ?\end{array}$ & 1 & 2 & 34 & 5 \\
\hline \multicolumn{5}{|l|}{ VIII Procedures } \\
\hline $\begin{array}{l}\text { Are all processes described in Standard Operating Procedures } \\
\text { (SOP) and are they observed? }\end{array}$ & 1 & 2 & 34 & 5 \\
\hline Are regular internal audits carried out? & 1 & 2 & 34 & 5 \\
\hline $\begin{array}{c}\text { Is the corrective and preventive actions system implemented for the } \\
\text { observed non-conformities? }\end{array}$ & 1 & 2 & 34 & 5 \\
\hline
\end{tabular}




\section{APPENDIX 2}

Indicators of expert group members 'agreement on the answers ( $\%$ of agreement, $n=14$ )

\section{Vaccine arrival}

Are there pre-shipment and arrival procedures in place?

Is a satisfactory contingency plan in place in case:

1) flights are delayed; 2) the airport cold room has failed or 3) transport to the store is delayed?

Are cold rooms adjusted for vaccine storage

(large enough to accommodate the largest anticipated vaccine shipment, have a secure lock,

have a continuous temperature recording device)?

Have staff received training in vaccine storage and transport?

Is every vaccine arrival recorded?

\section{Vaccine storage}

Do the employees that handle the vaccines know the correct storage temperature range

for each of the vaccines?

Do the employees that handle the vaccines know which vaccines

will freeze at temperatures below $0^{\circ} \mathrm{C}$ ?

Is there a complete set of manual temperature records for each and every cold room?

Is there a tested contingency plan in the event of equipment failure?

Is the plan rehearsed at least once a year?

\section{Cold storage capacity}

Has the volume calculation been carried out for all vaccines stored?

Have capacities of all cold rooms been calculated?

\section{Buildings, equipment and vehicles}

Is there a separate packing area close to the cold rooms and the needed packing material?

Is there sufficient space to store packed cold boxes in, or close to the packing area

and can the temperature of the packing area be maintained

between $15^{\circ} \mathrm{C}$ and $25^{\circ} \mathrm{C}$ throughout the year?

Do the refrigerated vehicles have an up-to-date service record 
and are the vehicles fitted

with continuous temperature recorders?

Are all cold rooms fitted with adequate shelving and alarm systems?

Have workers received training in safe working in cold rooms?

Is there an adopted refrigeration equipment replacement plan in place?

\section{Building, equipment and vehicle maintenance}

Are there building, equipment and vehicle maintenance plans? 79

Are there records of building, equipment and vehicle maintenance? 79

Is there an adopted preventive maintenance plan in place? 86

Are there records of preventive maintenance plan realization? 86

Are there any procedures for handling in case of equipment failure? 86

Are in-house cold room performance checks carried out twice a year

in extreme temperature conditions? $57^{*}$

\section{Stock records}

Are records about the type, number (in doses), manufacturer, batch/lot number, expiry date of the freeze-dried vaccine and diluent individually maintained? 93

Do stock records indicate adherence to EEFO principles (earliest expiry, first out)? 86

Are damaged/expired vaccines clearly identified in the stock recording system? 79

Are stock records data backed up as per the determined dynamics? 86

\section{Effectiveness of vaccine deliveries to the next level of distribution}

Did the primary store send a programme (announce delivery) to the intermediate store setting out dates for the delivery and/or collection of vaccines?

Is the reliability of actual delivery/collection dates against the programme between $90 \%$ and $100 \%$ ?

\section{Procedures}

Are all processes described in Standard Operating Procedures (SOP)

and are they observed?

Are regular internal audits carried out?

Is the corrective and preventive actions system implemented

${ }^{*}$ Agreement rate below the pre-defined criteria excluded the question from the questionnaire. 